\title{
La presencia de Góngora en el pensamiento poético de José Ángel Valente ${ }^{1}$
}

\author{
Margarita García Candeira \\ Universidad de Huelva
}

Título: La presencia de Góngora en el pensamiento poético de José Ángel Valente.

Resumen: Resumen: Este artículo analiza la interpretación que José Ángel Valente realiza de la personalidad poética y vital de Luis de Góngora. Partiendo especialmente de la obra ensayística del poeta gallego y de su biblioteca personal, trata de encuadrar la lectura valenteana en una serie de coordenadas críticas, personales y estéticas específicas, muy relacionadas por un lado con la poética de la retracción de Valente, de presupuestos antagónicos a la gongorina, así como con su experiencia biográfica y aproximación intelectual al exilio hispánico.

Palabras clave: José Ángel Valente, Luis de Góngora, Soledades, Exilio, Retracción.

Fecha de recepción: 24/9/2014.

Fecha de aceptación: 27/10/2014.
Title: The presence of Góngora in José Ángel Valente's poetic thought.

Abstract: This article analyses José Ángel Valente's interpretation of Luis de Góngora's poetic and vital personality. Departing mainly from Valente's theoretical production and from the observation of his private library, it tries to frame Valente's reading within a series of critical, personal and aesthetic coordinates. These are intimately linked to Valente's own poetics of retraction, which are antagonistic to Góngora's, and to his biographical experience and intellectual approach to Hispanic exile.

Key words: José Ángel Valente, Luis de Góngora, Soledades, Exile, Retraction.

Date of Receipt: 24/9/2014.

Date of Approval: 27/10/2014.

1 A Julián Jiménez Heffernan. 
En un trabajo sobre la relación de José Ángel Valente con los poetas metafísicos ingleses, Julián Jiménez Heffernan llama la atención sobre el impulso centrífugo que impele a la crítica a buscar los referentes de la obra valenteana en tradiciones foráneas (la mística, la judía, la árabe, las diversas literaturas europeas), produciendo entonces "un aislamiento intolerable de Valente con respecto a sus precursores reales" ${ }^{2}$; entre estos cita a San Juan, a Juan Ramón, a Machado, a Unamuno, a Lorca, pero también a Quevedo y, más llamativamente, a Góngora. Sin duda esta descompensación a la que se refiere Jiménez Heffernan tiene mucho que ver con la propia voluntad autorial de construir una figura caracterizada por cierta desterritorialización cosmopolita, pero lo cierto es que genera una laguna de desatención crítica en la que este artículo pretende adentrarse. El objetivo no es sino analizar la interpretación que, desde la segunda mitad del siglo XX, Valente realiza de la poesía y significación de Góngora en la historia, no solo literaria, de las letras españolas. Para ello, parto de tres recursos o fuentes fundamentales que testimonian el interés (no necesariamente unido al aprecio, como se verá) del poeta orensano por el autor de las Soledades. Son, en primer lugar, varios los ensayos en los que Valente perfila, con mayor o menor precisión y profundidad, la personalidad poética y vital de Góngora; en segundo lugar, la publicación en 1959, por parte de Valente y en colaboración con Nigel Glendinning, de una copia desconocida de las Soledades que ambos hallaron en la Biblioteca Bodleiana de Oxford. En tercer lugar, se empleará el valioso testimonio que suponen los libros de y sobre Góngora atesorados en su biblioteca personal, hoy custodiada en la Cátedra J. Á. Valente de la Universidad de Santiago de Compostela. El propósito de este trabajo es sobre todo desbrozar las claves de la aproximación de Valente a Góngora y situarlas en unas determinadas coordenadas críticas, pero también personales y poéticas que las hagan comprensibles, renunciando a enjuiciar en modo alguno la adecuación de los juicios valenteanos.

La lectura que Valente hace de Góngora se caracteriza, en primer lugar, por una disociación clave entre la obra y la persona, entre la escritura y la biografía del escritor barroco. Valente tiene una impresión negativa

2 Julián Jiménez Heffernan, "Barro que te reclama: Valente y los metafísicos ingleses”, Cuadernos Hispanoamericanos, 600 (2000), pp. 11-18 (p. 14). 
de la poesía gongorina, que considera abigarrada y rígida, y no duda en considerar a Góngora como el autor más conservador y tradicionalista de nuestra historia literaria; para él, la cerrazón de su mundo poético lo aleja completamente de nuestra sensibilidad. Pero, al tiempo, Valente muestra respeto e interés por un personaje al que dota de una heterodoxia esquiva (dada por su posible ascendencia conversa y por su vejez pobre y marginada por el poder) y una altura intelectual, pero sobre todo moral y ética, que lo elevan por encima de una Espańa pacata, cerrada y excluyente. Por esta supuesta subalternidad elitista y orgullosa halla Valente una vía de rehabilitación de Góngora, quien pasa a ser, de modo muy nítido, una figura especular en la que procura un reflejo de sus propias circunstancias históricas y vitales. Esta visión general que se acaba de perfilar está a su vez inflexionada por una evolución: parece como si el creciente aprecio de la vida del poeta influyera en una progresiva valoración de su obra. Pero lo fundamental es señalar que esta visión supone una cristalización magmática de posiciones críticas rastreables, que son el sustrato que Valente adapta y tamiza, con el fuerte sesgo valorativo y parcial de la lente interesada de sus propias ideas poéticas. Estas páginas tratarán de identificar estas fuentes críticas y de comprender la función que cumplen en la estética del autor de Material memoria. En primer lugar, se perfilará la visión que Valente expone de la obra de Góngora y de su significación; a continuación, se analizará la interpretación que hace de su figura biográfica. La posible convergencia de ambas lecturas en una poética compartida por ambos autores será objeto de unas breves y provisionales hipótesis finales.

En 1965, Valente, que vivía desde 1958 en Ginebra, publica en Ínsula un texto sobre la evolución de Miguel Hernández desde lo que él considera el pastiche barroco hasta el verso fresco y popular de Viento del pueblo; en él se encuentran las palabras más duras contra Góngora. Para explicar los inicios poéticos de Hernández, Valente hace referencia al influjo del poeta cordobés sobre los autores del 27 en los siguientes términos, sumamente peyorativos. La cita es extensa, pero muy representativa:

Son los años del Centenario de Góngora. Los centenaristas, vistos desde la perspectiva actual [1965], tienen un marcado signo conservador. La novedad o ímpetu de vanguardia con que puedan haber irrumpido en su medio nada quiere decir en contra de la anterior afirmación. Literariamente, el Centenario es un pronunciamiento en 
favor del poeta de visión más retraída y angosta entre los que pueden representar la compleja herencia de nuestro Siglo de Oro. La genialidad de Góngora consiste en cierto modo en haber agotado casi de golpe las posibilidades de elaboración o transfiguración arbitraria de la realidad para ajustarla a la categoría o valor parcial de la belleza. Góngora opera sobre las formas más aparienciales de lo real; poeta del enigma verbal, lo es escasamente de la realidad enigmática. La poesía de Góngora se impone más como lujo o dosel de la realidad manifiesta que como necesidad de manifestación de la realidad oculta. Es evidente que, en ese sentido, son Las Soledades su obra maestra. El proceso de autonomía o suficiencia de la forma artística parece alcanzar en el poeta cordobés sus límites extremos. Por eso hay en la genialidad de Las Soledades algo aberrante, casi agresivamente monstruoso, obsesivo como un laberinto cuya salida se hubiese condenado ${ }^{3}$.

Una idea similar se repite de modo muy escueto en "La necesidad y la musa", un texto de 1963, donde Valente, al hablar de la necesidad que tuvieron los del 27 de convertir, tras la guerra, la "experiencia solitaria en experiencia solidaria", explica que Alberti rompe abruptamente con "los supuestos conservadores del centenario de Góngora”“. Se pueden repasar las acusaciones hechas a don Luis: la de generar una poesía en la que la complejidad de la forma o del lenguaje (lo que Valente denomina el "enigma verbal") no es solidaria con una profundidad intelectual sino tan solo con un contenido banal e intrascendente: se queda en "las formas más aparienciales de lo real" pero no indaga en "la realidad enigmática” o en "la realidad oculta". Este reparo está también en la base de otros acercamientos parciales a la obra de Góngora y lo propio vale, indirectamente, por lo que atañe a su aprecio por Quevedo, a quien considera dotado para la complejidad intelectual de la que Góngora carecería 5 .

3 José Ángel Valente, "Miguel Hernández: poesía y realidad”, en Obras completas II. Ensayos, ed. Andrés Sánchez Robayna, recopilación e introducción de Claudio Rodríguez Fer, Barcelona, Galaxia Gutenberg, 2006, pp. 176-185 (p. 177).

4 José Ángel Valente, "La necesidad y la musa”, en Obras completas II. Ensayos, ed. Andrés Sánchez Robayna, recopilación e introducción de Claudio Rodríguez Fer, Barcelona, Galaxia Gutenberg, 2008, pp. 158-165 (p. 163).

5 De hecho, Valente considera que uno de los detonantes en la evolución de Miguel Hernández hacia una poesía más "descarnada y directa" es precisamente la influencia creciente de Quevedo en él. José Ángel Valente, "Miguel Hernández: poesía y 
Así, en un artículo sobre el Cántico de Guillén, escrito entre 1967 y 1970 (al menos dos años después del texto anterior), Valente muestra su reticencia ante un mundo poético caracterizado por el ajuste, el ensamblaje perfecto de piezas que expulsa cualquier vacío o cualquier desorden. Valente explica que Guillén se apoya en Góngora, pero, de modo ciertamente significativo, se inhibe a la hora de ratificar o no el juicio de Guillén sobre la ascendencia gongorina de la "geométrica precisión” de su mundo poético. Escribe:

Pero el propio Guillén no ha sido insensible -y no ya como poeta, sino como expositor de otros poetas- a esa forma de geométrica precisión que caracteriza su obra. Acaso él mismo la buscó en quienes pudo haber considerado como modelos. Tal es el caso de Góngora. A Góngora ha transferido Guillén (no es éste lugar para discutir el acierto de esa operación crítica) su propia visión del movimiento creador como adecuación o ajuste ${ }^{6}$.

Valente se refiere aquí a unas páginas de Lenguaje y poesía, libro de 1961 que recoge las conferencias dictadas por Guillén en la Cátedra Charles Eliot Norton de Harvard. En el capítulo dedicado a Góngora, Guillén definía la poesía del cordobés como "un lenguaje construido como un objeto enigmático, en todo su rigor” y destacaba la dimensión espacial,

realidad", pp. 180-181. En "La formación del escritor como profesional", un texto procedente del archivo del autor cuya segunda parte se compuso en Oxford en 1956, Valente propone a Quevedo como "de todos nuestros clásicos el más próximo a la preocupación y al sentir contemporáneos" y hace de él ejemplo del valor añadido que la formación intelectual y humanística supone para todo escritor. José Ángel Valente, "La formación del escritor como profesional", Obras completas II. Ensayos, pp. 1036-1048 (pp. 1039-1040). La admiración por el autor de los Sueños se debe también al aprecio de su supuesta actitud contestataria y crítica ante el poder, como se deduce del retrato poetizado en la composición "A don Francisco de Quevedo, en piedra”, incluido en la colección Poemas a Lázaro. José Ángel Valente, Obras completas I. Poesía y prosa, ed. e introducción de Andrés Sánchez Robayna, Barcelona, Galaxia Gutenberg, 2008, pp. 103-160 (pp. 143-145).

6 José Ángel Valente, “Cántico o la excepción de la normalidad”, en Obras completas II. Ensayos, pp. 118-124 (p. 120). 
arquitectónica y material de sus versos ${ }^{7}$. En particular, señalaba una característica que parece hermanar la obra poética de ambos autores, y que Valente cita en su ensayo, sobre la condición optimista, armónica y ajustada del mundo estético gongorino: "Sus infinitos hallazgos -dice Guillén en unas palabras que cita Valente- nacen acordes a la visión más sana, más equilibrada de esa realidad que acepta y disfruta".

El título del texto sobre Miguel Hernández era precisamente el de "poesía y realidad" y, en efecto, son las relaciones entre ambos términos las que nos pueden dar la clave de la censura de Góngora, que tiene sus fuentes en posturas críticas muy destacadas: las de Dámaso Alonso, Alfonso Reyes o el propio Guillén, pero que Valente adapta a una poética que se sitúa en el lado opuesto de la gongorina. De todos ellos posee títulos en su biblioteca personal; Dámaso fue, además, su profesor de Filología Románica. Y las ideas de todos ellos son la base de las de Valente: hemos visto que su ataque se dirigía en primer lugar a la desproporción entre un lenguaje concebido como "enigma verbal" que no se correspondía con una profundidad intelectual. Esta opinión, que se remonta a reprobaciones ya presentes en los primeros comentaristas contemporáneos al poeta cordobés, encuentra sin embargo un amparo más directo en formulaciones de Guillén, Dámaso y Alfonso Reyes, como veremos a continuación. Valente poseía las obras completas del mexicano, a quien encomia diciendo que Góngora no había tenido un comentarista tan lúcido como él hasta el Lezama Lima de "Sierpe de don Luis de Góngora", incluido en Analecta del reloj y publicado en $1937^{9}$. Y Reyes había expresado una idea similar a la de Valente cuando observa, en "Sabor de Góngora", que "el cultismo es una exacerbación verbal”, un "preciosismo lingüístico", mientras que el conceptismo quevediano era una "exacerbación ideológica" ${ }^{10}$. De modo relacionado, el desprecio hacia una poesía que recoge contenidos banales

7 Jorge Guillén, Lenguaje y poesía: algunos casos españoles, Madrid, Alianza Editorial, 1972, p. 35.

8 Ibidem, p. 69.

9 José Ángel Valente, "Lezama: una imagen”, en Obras completas II. Ensayos, pp. 1276-1279 (p. 1277).

10 Alfonso Reyes, "Sabor de Góngora", en Obras completas VII, México, Fondo de Cultura Económica, 1958, pp. 171-198 (p. 189). Es un texto publicado por primera vez en 1928. 
e intrascendentes late en las referencias de Dámaso Alonso al rechazo de lo humano que alejó a Góngora del romanticismo y del naturalismo ${ }^{11}$, y en la siguiente advertencia de Guillén:

No busquemos en los grandes poemas algo sobre Dios, el alma, nuestro destino, porque esos poemas no se desenvuelven en dirección religiosa, metafísica, psicológica, moral. Don Luis nos ofrece -nada más, nada menos- una visión hermosa de la Naturaleza ${ }^{12}$

De ahí probablemente la impresión de caducidad y anacronismo de una poesía que, para Reyes y Dámaso, en una idea que hereda Valente, está muy lejos de nuestra sensibilidad. "No es ya nuestro poeta", dice Reyes, porque "su filosofía de la vida nos sirve de muy poca cosa"13.

Pero la acusación, con tintes ideológicos, de conservadurismo a la poesía gongorina se debe al carácter dado, preexistente e inmutable de la realidad que conforma su mundo poético, que produce una sensación de clausura y asfixia. De algún modo, el pormenorizado análisis retórico y tropológico que realiza Dámaso de la obra de Góngora, así como su defensa de una dificultad franqueable en detrimento de la tan aireada oscuridad gongorina, presentan una poesía concebida como un jeroglífico cuya solución o sentido existe, de antemano, a la espera de que la técnica del lector lo encuentre, pero nunca lo cree o recree. Además, Dámaso lo explicita: en "Góngora y la literatura contemporánea”, y precisamente a raíz de la manida comparación con Mallarmé que hicieron los defensores de la poesía pura de principios del XX, Dámaso deja claro que "para Góngora el mundo de representaciones estéticas es un complejo formado, preexistente, tradicional", mientras que para el francés es "un mundo inexistente, que se está formando y deshaciendo en todo momento de intuición poética, vario, nuevo siempre, cambiante..."14. Quizás por ello, y esta vez en otro texto, "Dos trabajos gongorinos de Alfonso Reyes", no dude en tildar a Góngora de "revolucionario, como todo creador de una

11 Dámaso Alonso, "Góngora y la literatura contemporánea", en Estudios y ensayos gongorinos, Madrid, Gredos, 1970, pp. 518-566 (p. 520).

12 Jorge Guillén, op. cit., pp. 68-69.

13 Alfonso Reyes, op. cit., p. 194.

14 Dámaso Alonso, op. cit., p. 531. 
nueva forma artística” pero, también, de “el más conservador de nuestros poetas" porque, señala, "la nota central de su arte es la de ser perfección, síntesis, condensación de anteriores elementos renacentistas" ${ }^{15}$. Como vemos, se trata de un diagnóstico idéntico al de Valente, aunque la carga valorativa quede más suspendida o atenuada. En el seno de este juicio sobre la condición de la realidad poética se puede situar el contraste que Valente (apoyándose nuevamente en Lezama) traza entre San Juan, que efectúa la "destrucción del sentido" con un lenguaje intransitivo, y Góngora, que procura el "esplendor del sentido", que aparece como estático, inmutable y exhaustivo ${ }^{16}$.

Evidentemente, Valente se alinea con el primero en la defensa de una realidad poética dialéctica y en movimiento, que viene posibilitada por un lenguaje que renuncia a la clausura semántica para, al contrario, procurar una grieta o vacío que aparece como matriz creadora. Se pueden encontrar numerosas variaciones de esta idea sobre la que pivota su poética. No hay que olvidar la definición que propone de la mandorla, símbolo matricial con el que da título a su poemario de 1982, como "espacio vacío y fecundante" en un ensayo, "La experiencia abisal", escrito en 1999, que es un auténtico recorrido sobre distintas formulaciones filosóficas y antropológicas del poder germinativo de la nada. Esta misma idea está presente en "El arte como vacío", entrevista que hace a Chillida en colaboración con Francisco Calvo Serraller, y en "A propósito del vacío, la forma y la quietud", otro texto teórico incluido en Notas de un simulador (1989-2000). Y de ella dan testimonio estas célebres frases de los "Cinco fragmentos para Antoni Tàpies" incluidos en Material memoria, de 1979:

15 Dámaso Alonso, "Dos trabajos gongorinos de Alfonso Reyes", en Estudios y ensayos gongorinos, pp. 509-517 (p. 510).

16 José Ángel Valente, "Juan de la Cruz, el humilde del sinsentido", en Obras completas II. Ensayos, pp. 307-310 (p. 309-310). Valente establece el contraste entre ambos en los siguientes términos: "A este límite extremo de la palabra nunca se ha llegado, dentro de la tradición nuestra, de más radical manera que en el caso de Juan de la Cruz. Radicalidad de la palabra, radicalidad de la experiencia. Se ha buscado o visto la radicalidad última de la palabra poética nuestra en Góngora. Es en Juan de la Cruz -sin perjuicio de la grandeza poética del cordobés- donde hay que buscarla" (p. 309). 
Quizá el supremo, el solo ejercicio radical del arte sea un ejercicio de retracción [...] Crear es generar un estado de disponibilidad, en el que la primera cosa creada es el vacío, un espacio vacío. Pues lo único que el artista acaso crea es el espacio de la creación. Y en el espacio de la creación no hay nada (para que algo pueda ser en él creado). La creación de la nada es el principio absoluto de toda creación ${ }^{17}$.

Es obvio que Valente no parece encontrar en la obra de Góngora ningún valor que le sirva de referencia para su propia poética; por supuesto, reconoce la importancia del autor del Polifemo para la historia literaria. Pero esa lejanía estética puede explicar que, en sus ediciones de las Soledades ${ }^{18}$, solo encontremos marcas de lectura en la realizada por Dámaso Alonso (Valente maneja la tercera edición, de 1956, de un trabajo que había sido originariamente publicado en 1927) y que estas se relacionen con los cotejos efectuados para situar en la historia textual la copia manuscrita (con variantes de autor) que Valente halló en la Biblioteca Bodleiana de Oxford y presentó en 1959, en un artículo de Bulletin of Hispanic Studies escrito junto a Nigel Glendinning ${ }^{19}$. A este respecto hay que señalar un episodio de cierta relevancia para la historia externa de la crítica: el conflicto que surgió entre Dámaso y Valente a raíz de este hallazgo documental del poeta gallego. Dámaso se encontraba preparando una nueva edición de las Soledades para la que contaba con el manuscrito principal

17 José Ángel Valente, Obras completas I. Poesía y prosa, p. 387.

18 En la Cátedra José Ángel Valente de la biblioteca de Filología de la Universidad compostelana se conservan hasta cuatro ediciones de esta obra: la ya mencionada de Dámaso Alonso (Las Soledades, Madrid, Sociedad de Estudios y Publicaciones, 1956, $3^{\text {a }}$ ed.); la publicada por Robert Jammes en 1994 (Soledades, Madrid, Castalia, 1994); la que preparó John Beverley en 1979 (Soledades, Madrid, Cátedra, 1979) y, por último, la edición que de nuevo Dámaso Alonso publicaría en 1982 y que es una reproducción del trabajo de 1927. Además, se guardan ejemplares de los sonetos gongorinos (Sonetos completos, edición, introducción y notas de Biruté Ciplijauskaité, Madrid, Castalia, 1981), la edición que Alexander Parker hizo del Polifemo (Fábula de Polifemo y Galatea, Madrid, Cátedra, 1983), la reproducción del manuscrito Chacón: Obras de Don Luis de Góngora. Manuscrito Chacón, Madrid, Real Academia Espańola, 1991-1992); y la cuarta edición de las Obras completas (Madrid, Aguilar, 1956) dispuestas por Juan e Isabel Millé y Giménez.

19 José Ángel Valente y Nigel Glendinning, "Una copia desconocida de las Soledades de Góngora”, Bulletin of Hispanic Studies, XXXVI, 1 (1959), pp. 1-14. 
de Díaz de Rivas. Ambos se requieren recíprocamente sus materiales, ninguno de los dos cede y sus trabajos se publican por separado. El episodio deja un intercambio de cartas inéditas que ha reproducido parcialmente Fernández Rodríguez en la primera entrega de Valente vital, la biografía del poeta publicada en $2012^{20}$. Esto origina un distanciamiento personal que venía a dilatar la reticencia de Valente hacia Dámaso, al que consideraba un profesor mediocre (así lo dice en una entrevista ${ }^{21}$ ) y del que le iban separando cada vez más convicciones poéticas y críticas ${ }^{22}$. Esta antipatía creciente tiene uno de sus frutos en el poema "Dámaso Alonso: imagen sucesiva”, de 1970.

Pero, volviendo a la poética, lo que Valente echa en falta es precisamente la falta, la grieta o el respiradero por el que se quiebre la clausura asfixiante de sus versos. Y la encontrará precisamente en la vida de Góngora, en la supuesta heterodoxia de un poeta anciano sumido en la pobreza, casi en el olvido, y que debe conducirse según las normas del disimulo para ocultar su ascendencia judía. Valente construye una imagen de Góngora como exiliado interior que procede de una lectura muy interesada y selectiva de determinadas fuentes, y que parece remitir a su intento de establecer un paralelo con su propia situación personal (de desengaño y de retiro) e histórica (respecto a una Espańa caracterizada por la cerrazón opresora).

En "Oráculo manual o arte de la persona” (escrito en 1992) Valente desarrolla un argumento que encuentra ecos en otros lugares de sus ensayos.

20 Claudio Rodríguez Fer (ed.), Valente vital (Galicia, Madrid, Oxford), Santiago de Compostela, Publicaciones de la Cátedra José Ángel Valente de Poesía y Estética de la Universidade de Santiago de Compostela, 2012.

21 Sobre sus ańos en la universidad madrileńa, le dice Valente a Claudio Rodríguez Fer en la entrevista que este le hizo a finales de los 90: "Tamén ensinaba alí Dámaso Alonso, pero Dámaso repetía sempre as mesmas cousas, non facía cursos novos". José Ángel Valente y Claudio Rodríguez Fer, "Entrevista a José Ángel Valente: de Ourense a Oxford”, Moenia, 4 (1998), pp. 451-464 (p. 460).

22 Se podría decir que Valente echa en falta en Dámaso, y muy probablemente en la crítica española, que no se trascendiera el exhaustivo análisis retórico y estilístico con una atención a los problemas intelectuales y filosóficos que reflejan los textos. Se lo reprocha al trabajo crítico que Dámaso realiza sobre San Juan, y enmarca dicha carencia en "la falta de relación entre poesía y pensamiento, [...] grave y persistente de nuestra modernidad". Cf. José Ángel Valente, "Formas de lectura y dinámica de la tradición”, en Obras completas II. Ensayos, pp. 703-712 (p. 708). 
Aquí, sitúa a Gracián en el conjunto de una serie de personajes del XVII caracterizados por una posición de marginalidad o desajuste: son "grandes figuras veladas o secretas" entre las que está "el enigmático y cerrado personaje que fue Góngora"23 (657). Esta condición dislocada del cordobés viene dada, en primer lugar, por la marginación creciente respecto al poder y por una vejez lastrada por las penurias económicas. Así,

no sólo el Góngora hermético e irónico de la memorable respuesta al obispo Francisco Pacheco: "que si mi poesía no ha sido tan espiritual como debiera, que mi poca teología me disculpa, pues es tan poca, que he tenido por mejor ser condenado por liviano que por hereje". Hablo también del Góngora del regreso de la Corte a Córdoba, después del brutal acuchillamiento de Villamediana, harto de pretender y simular y de halagar y de no recibir, el Góngora enfermo que, a fuerza de borrarse o ser borrado, pierde toda memoria de sí: "el poeta espańol -dice Spinoza en el escolio de la proposición XXXIX de la Ética- que había caído enfermo y que, aunque ya curado, entró en tal olvido de su vida pasada que no creía que las narraciones y las tragedias que había compuesto fuesen obra suya". Tal sucedía un año antes de su muerte en 1627. El poeta enigmático perdido en los laberintos de su desmemoria. ¿Borraba así todo rastro de su persona humillada, de su perfil de fracasado pretendiente en un mundillo paseado por la arrogancia estúpida o brutal del hombre de poder? ${ }^{24}$.

A continuación, Valente explica la obra de Gracián desde la necesidad de desarrollar un comportamiento discreto, prudente, caracterizado por la opacidad y el recato, para esquivar los mecanismos metamorfoseantes del omnímodo poder absolutista: el Oráculo manual es ante todo "un arte de la supervivencia individual", una auténtica "ética de la ocultación" para la que Valente halla conexión con la "teología del secreto" propuesta por Yerushalmi a propósito del "encubrimiento sistemático de su propia espiritualidad criptoejercida por los marranos espańoles en los siglos XVI y XVII"25. Es decir, lo que ocultaban o disimulaban era su condición con-

23 José Ángel Valente, "El «Oráculo manual» y el arte de la persona”, en Obras completas II. Ensayos, pp. 656-662 (p. 657).

24 Ibidem, p. 657.

25 Ibidem, p. 661. 
versa. Y en un artículo algo posterior sobre Edmond Jabès, Valente es aún más explícito a la hora de explicar que este modus vivendi defensivo de los conversos se hacía de algún modo patente en figuras como Cervantes o el mismo Góngora:

En ese clima -suficientemente documentado en la historia y en la literatura- de inestabilidad social y psíquica, se desarrolla un estilo o arte de ser persona que en otras ocasiones he llamado la "ética de la ocultación” y que, a mi entender, podría tener manifestación notoria en los esquivos o resbaladizos perfiles biográficos de personajes de tan densa significación como Cervantes o Góngora, por no mencionar a Fernando de Rojas o a Isaac Cardoso, objeto este último de una obra tan reveladora del tema que aquí nos ocupa como la de Yosef Yerushalmi ${ }^{26}$.

La cuestión de la ascendencia judía de Góngora ha sido profusamente estudiada, pero la biblioteca de Valente nos deja dos testimonios valiosos: acostumbrado a subrayar y anotar sus libros, vemos que marca solamente las referencias a cuestiones biográficas en las monografías de Robert Jammes y de Emilio Orozco. En el libro de Jammes, La obra poética de don Luis de Góngora y Argote, de 1987, señala el capítulo "Prosperidad y decadencia" y los pasajes sobre la conveniencia económica de hacerse racionero en $1602^{27}$, su decisión de hacerse sacerdote ante el empobrecimiento familiar $^{28}$ o su afición al juego ${ }^{29}$. Pero las más significativas son las marcas en las páginas donde Jammes alude a la condición judía de la abuela materna del poeta (Anexo I) ${ }^{30}$ y a la supuesta insensibilidad gongorina ante los rumores sobre su condición (Anexo I y II) ${ }^{31}$.

Algo muy similar sucede con el libro de Orozco, Introducción a Góngora, cuya edición de 1984 emplea Valente. En él señala la referencia a

26 José Ángel Valente, “Edmond Jabès: judaísmo e incertidumbre”, en Obras completas II. Ensayos, pp. 662-673 (pp. 668-669).

27 Robert Jammes, La obra poética de don Luis de Góngora y Argote, Madrid, Castalia, 1987, p. 14.

28 Ibidem, p. 17.

29 Ibidem, p. 19.

30 Ibidem, p. 22.

31 Ibidem, pp. 22-23. 
la amnesia final del cordobés ${ }^{32}$, la respuesta a la carta de Pacheco ${ }^{33}$, pero sobre todo el apartado "Sobre la supuesta ascendencia de Góngora de "cristianos nuevos»" y la conclusión de Orozco sobre una incidencia real de esta en su personalidad, pues podría haber causado inhibiciones biográficas y poéticas en su comportamiento. Destaca un párrafo en el que el crítico afirma que "algo profundo de la psicología de don Luis respondió a esa condición, aunque fuese confusa, de su origen de judaizante" (Anexo III $)^{34}$. Es palmario que son justamente las ideas que Valente emplea para conformar el retrato vital de Góngora ya visto. Pero, además, se traslucen las tesis de Américo Castro, a quien Valente leyó con atención (posee numerosos ejemplares en la biblioteca, aunque sin marcas ${ }^{35}$ ), cuyo libro La realidad histórica de España había reseñado ya en $1955^{36}$, y a quien conoció personalmente durante su estancia en Oxford, en algún momento de sus años entre el 55 y el 58, por mediación de Jiménez Fraud, con el que Valente tuvo mucho contacto. En una entrevista realizada en 1999, recuerda que el antiguo director de la Residencia de Estudiantes fue quien se lo presentó en su casa, aunque no precisa la fecha ${ }^{37}$.

Es precisamente desde este contexto desde donde comprenderemos mejor la naturaleza de la lectura selectiva de Valente: son textos escritos en

32 Emilio Orozco Díaz, Introducción a Góngora, Barcelona, Crítica, 1984, p. 54.

33 Ibidem, pp. 33-34.

34 Ibidem, pp. 150-151.

35 Así, se conservan custodiados en la mencionada Cátedra los volúmenes Aspectos del vivir hispánico, Madrid, Alianza, 1970; De la edad conflictiva, Madrid, Taurus, 1961; España en su historia. Cristianos, moros y judios, Buenos Aires, Losada, 1948; Españoles al margen, Madrid, Júcar, 1973; El pensamiento de Cervantes, Barcelona, Noguer, 1972 y La realidad histórica de España, México, Porrúa, 1954.

36 Con el título de "Una nueva versión de España en su historia" se publica la recensión, muy laudatoria, que Valente realiza de La realidad histórica de España, la obra que Castro publica en 1954 y que era una versión corregida de España en su historia. Cristianos, moros y judios, editada por primera vez en 1948. José Ángel Valente, "Una nueva versión de España en su historia", Cuadernos Hispanoamericanos, 68-69 (1955), pp. 268-273.

37 Cuenta a José Méndez sobre su relación con Jiménez Fraud: "Allí en su casa conocí a Américo Castro. [...] Con su exquisita educación te decía: «venga esta tarde que a Américo le interesará mucho conocerle»". Cf. José Ángel Valente y José Méndez, "Siempre he querido estar solo: Entrevista a José Ángel Valente", Revista Residencia, 8, 1999. Enlace: www.residencia.csic.es/bol/num8/valent.htm. 
sus años de Oxford (1955-58) y Ginebra (1958-1985), es decir, durante su exilio voluntario y, algunos, ya en sus años de Almería (en donde se instala en 1985). El exilio aparece en Valente como una noción compleja sobre la que se cifra una triple proyección: histórica, personal o autorial y poética: de ella son indicativas múltiples formulaciones que hallan una síntesis muy elocuente en el ensayo "Poesía y exilio", que Valente leyó como ponencia inaugural del encuentro internacional sobre el exilio poético español en México, celebrado en la capital del país en mayo de 1993.

Valente comienza estableciendo una analogía explícita entre la España áurea y la de posguerra: apoyándose en Bataillon ${ }^{38}$, explica que un mismo esplendor europeísta y aperturista es estrangulado en ambos casos por una represión que causa la dispersión de poblaciones que no casan con una idea monolítica de la españolidad. Desde el exilio del 39 se reflexiona sobre el exilio de los judíos tras 1391 y 1492, y Valente participa en una contralectura de la historia mostrando su especial atracción por los elementos amputados; evidentemente, esta postura se halla en consonancia con su atención creciente a la tradición mística, judía y árabe durante esos años y a su defensa como constitutivas de una europeidad más amplia e integral.

En el seno de esta analogía más amplia podemos localizar la proyección personal y autorial de Valente, que encuentra en Góngora, un auténtico exiliado interior, un correlato indirecto de su soledad marginal y orgullosa al mismo tiempo. Valente cierra el texto "Poesía y exilio" mentando la figura de Cernuda como ejemplo de esta misma cualidad. Pero es significativo que lo remate reproduciendo los versos finales del poema cernudiano "Góngora”, incluido en Como quien espera el alba (1947), que aluden a la condición "vencida" y "exaltada" del poeta cordobés que acaba perdido en el olvido:

38 "No le pareció posible a Marcel Bataillon concluir su Erasmo en España sin evocar lo que, desde el punto de vista de una renovación profunda de la vida española, tienen en común con el movimiento erasmista del siglo XVI tanto el movimiento krausista del siglo XIX como sus derivaciones inmediatas, la Institución Libre de Enseñanza sobre todo, que en una honda y lenta remoción de muy sumergidos sustratos llevan a la historia nuestra, en poco más de medio siglo, a los umbrales de la modernidad con la República de 1931". José Ángel Valente, Obras completas II. Ensayos, p. 678. 
Gracias demos a Dios por la paz de Góngora vencido; Gracias demos a Dios por la paz de Góngora exaltado; Gracias demos a Dios, que supo devolverle (como hará con nosotros), Nulo al fin, ya tranquilo, entre su nada ${ }^{39}$.

El resto del poema recrea la imagen de un Góngora caracterizado por una soledad asumida como precio de la independencia y de la conciencia de la propia valía: Cernuda presenta al poeta como "[e]l andaluz envejecido que tiene gran razón para su orgullo" y dice en otro verso que "[ya] restituye el alma a soledad sin esperar de nadie / Si no es de su conciencia [...]" ${ }^{40}$. La visión crítica de Valente es parcialmente similar -también es similar la situación vital y poética de Cernuda: exiliado en una universidad británica ${ }^{41}$, orgulloso y solitario ${ }^{42}$ - y con ella Valente participa, si bien crítica y no líricamente, en una línea contemporánea de interpretación de Góngora como un modelo ético más que poético que ha sido estudiada, entre otros, por Ponce Cárdenas, Trabado Cabado, Arellano o Roses Lozano ${ }^{43}$.

Pero el exilio, además, se une a la idea del vacío como clave de una poética basada en cierta espera carencial: "el acto creador", explica Valente en el mismo ensayo, "supone un movimiento exílico, una retracción, una distancia” en la que tiene lugar la promesa ${ }^{44}$. Se aproxima así a la noción de judeidad, que tiene también que ver con la escritura en la medida en

39 José Ángel Valente, Obras completas II. Ensayos, p. 690.

40 Luis Cernuda, "Góngora”, Antología poética, Madrid, Cátedra, p. 209.

41 Cernuda se marcha a Londres en 1938.

42 No hay que olvidar que Cernuda viaja a Londres en 1938 y que permanecerá como lector en la Universidad de Cambridge durante varios cursos.

43 Jesús Ponce Cárdenas, "Imagen de Góngora en cinco poetas contemporáneos", Dicenda. Cuadernos de Filología Hispánica, 18 (2000), pp. 295-318; José Manuel Trabado Cabado, "Pablo García Baena y la tradición áurea. Intertextos gongorinos y la mediación de Cernuda en tres poemas de "Fieles Guirnaldas Fugitivas»", Tropelías: Revista de Teoría de la literatura y Literatura comparada, 9-19 (1998-1999), pp. 439-459; Ignacio Arellano, "El poeta como paria social en Cernuda. Glosas al poema "Góngora»", Revista Signos, XXX, 41-42 (1997), pp. 5-27; Joaquín Roses Lozano, "Códigos, poética y ética en "Góngora» de Luis Cernuda", Glosa: Anuario del Departamento de Filología Española y sus Didácticas, 2 (1991), pp. 271-288.

44 José Ángel Valente, Obras completas II. Ensayos, p. 683. 
que ambas se sitúan para Valente en la espera del advenimiento, en una postura de apertura posibilitada por la incertidumbre. Justo lo que la poesía gongorina no tiene, según la visión valenteana.

Sin embargo, esta conexión entre creación y retirada, entre creación e inhibición, puede dejar un margen para una poética compartida que no podemos sino apuntar de modo absolutamente tentativo e hipotético. Podemos preguntarnos en qué medida la retracción está en la base de muchos procedimientos poéticos identificados en Góngora y que tienen que ver con la preterición y la reticencia: me refiero a la dialéctica entre alusión y elusión apuntada por Dámaso Alonso, a la prolijidad verbal que retrasa la idea según la formulación de Guillén, al mecanismo de la ocultación propuesto por Mercedes Blanco o al desplazamiento temático identificado por Orozco ${ }^{45}$. Explicaba Valente que la ética del ocultamiento era también una estética; en este punto pueden converger, tangencialmente y con muchos matices, los versos de Valente o Góngora y, por supuesto, convertirse en objeto para un trabajo ulterior.

45 Dámaso Alonso, "Alusión y elusión en la poesía de Góngora”, Revista de Occidente, 56 (1928), pp. 177-202; Jorge Guillén, op. cit., p. 41; Mercedes Blanco, "El mecanismo de la ocultación. Análisis de un ejemplo de agudeza”, Criticón, 43 (1988), pp. 13-36; Emilio Orozco, Manierismo y Barroco, Madrid, Cátedra, 1988, pp. 170-187. 